\title{
AMENDMENTS
}

\section{Author Correction: Carbon stocks in central African forests enhanced by elephant disturbance}

Fabio Berzaghi (D), Marcos Longo (D), Philippe Ciais (D), Stephen Blake, François Bretagnolle, Simone Vieira (D), Marcos Scaranello, Giuseppe Scarascia-Mugnozza and Christopher E. Doughty (D)

Correction to: Nature Geoscience https://doi.org/10.1038/s41561-019-0395-6, published online 15 July 2019.

In the version of this Article originally published, the first sentence of the Acknowledgements "We would like to thank D. Papale, M. Zapparoli, L. Portoghesi, M. di Porcia e Brugnera, and H. Verbeeck for feedback that helped improve the manuscript." should have been "We would like to thank: F. Berzaghi's PhD thesis committee: D. Papale, M. Zapparoli and L. Portoghesi; A. Swann and S. Wasser for their conception of this idea and their mentorship during the initial work on the project; and M. di Porcia e Brugnera and H. Verbeeck for feedback that helped improve the manuscript." This has now been amended.

\section{Author Correction: Thick ice deposits in shallow simple craters on the Moon and Mercury}

Lior Rubanenko (D), Jaahnavee Venkatraman and David A. Paige

Correction to: Nature Geoscience https://doi.org/10.1038/s41561-019-0405-8, published online 22 July 2019.

In the version of this Article originally published, in the sentence beginning "If all cold-traps..., ' $\sim 100$ million metric tons' should have been ' 100 billion metric tons'. This has now been amended.

Published online: 25 October 2019

https://doi.org/10.1038/s41561-019-0490-8

(C) The Author(s), under exclusive licence to Springer Nature Limited 2019 